\title{
Publisher Correction: The global distribution of tetrapods reveals a need for targeted reptile conservation
}

Uri Roll, Anat Feldman, Maria Novosolov, Allen Allison, Aaron M. Bauer, Rodolphe Bernard, Monika Böhm, Fernando Castro-Herrera, Laurent Chirio, Ben Collen, Guarino R. Colli, Lital Dabool, Indraneil Das, Tiffany M. Doan, Lee L. Grismer, Marinus Hoogmoed, Yuval Itescu, Fred Kraus, Matthew LeBreton, Amir Lewin, Marcio Martins, Erez Maza, Danny Meirte, Zoltán T. Nagy, Cristiano de C. Nogueira, Olivier S. G. Pauwels, Daniel Pincheira-Donoso, Gary D. Powney, Roberto Sindaco, Oliver J. S. Tallowin, Omar Torres-Carvajal, Jean-François Trape, Enav Vidan, Peter Uetz, Philipp Wagner, Yuezhao Wang, C. David L. Orme, Richard Grenyer and Shai Meiri

Correction to: Nature Ecology \& Evolution https://doi.org/10.1038/s41559-017-0332-2 (2017); published online 9 October 2017.

In this Article originally published, owing to a technical error, the author 'Laurent Chirio' was mistakenly designated as a corresponding author in the HTML version, the PDF was correct. This error has now been corrected in the HTML version. Further, in Supplementary Table 3, the authors misspelt the surname of 'Danny Meirte'; this file has now been replaced. 